\title{
Relative Contributions of Tropical and Mid-Latitude Signals on Intraseasonal Precipitation Anomalies Over South China in Boreal Winter
}

Lu Wang ( $\sim$ luwang@nuist.edu.cn )

Nanjing University of Information Science and Technology https://orcid.org/0000-0002-4811-8847 Jie Jiang

Nanjing University of Information Science and Technology

Tim Li

University of Hawai'i at Mānoa

\section{Research Article}

Keywords: Madden-Julian Oscillation, Mid-latitude intraseasonal oscillation, Precipitation, Southern China

Posted Date: January 11th, 2022

DOI: https://doi.org/10.21203/rs.3.rs-1201440/v1

License: (a) (1) This work is licensed under a Creative Commons Attribution 4.0 International License. Read Full License 


\section{Abstract}

The southern China (SC) exhibits a strong intraseasonal precipitation variability in boreal winter, but so far the relative contributions of the tropical Madden-Julian Oscillation (MJO) and the mid-latitude intraseasonal oscillation (ISO) is unclear. This issue is addressed through a cluster analysis. The result shows that $53 \%$ of strong intraseasonal precipitation events are unrelated to the MJO. They are caused by southward propagation of a low-pressure anomaly in the lower troposphere from higher latitudes. Southerly anomalies associated with the low-pressure system transport high mean moisture from South China Sea, leading to moisture accumulation over SC. $47 \%$ of the events are accompanied by the MJO, and they can be further divided into two groups: one with enhanced MJO convection over the eastern Indian Ocean (termed as IO group), and the other over the Maritime Continent (termed as MC group). For the IO group, the SC precipitation is triggered by low-level southerly anomalies associated with an anomalous anticyclone over the western North Pacific (WNP) in association with suppressed MJO convection in situ, as well as the upper-tropospheric divergence related to a wave train excited from the MJO convection. For the MC group, both the upper-tropospheric wave train related to MJO and the southward propagation of low-pressure anomaly from higher latitudes in the lower troposphere contribute to trigger the SC precipitation.

\section{Introduction}

In boreal winter, most parts of the eastern China are characterized by dry and cold conditions as influenced by the East Asian winter monsoon, whereas the southern China (SC) has abundant precipitation due to ample moisture. In the recent past years, several extreme wet winters occurred over SC such as the beginning of 2008 and 2010, which caused extensive damage and serious direct economic losses (e.g., Tao and Wei 2008; Yao and Huang 2016). These extreme cases were all featured by long-lasting precipitation, in which the intraseasonal scale was an important mode (Hong and Li 2009; Wu et al. 2009; Yao et al. 2014). Further spectrum analysis of daily time series of SC-averaged precipitation during boreal winter using long-term observed data also showed significant peaks within the intraseasonal period band. On average, the intraseasonal component of precipitation could account for about $50 \%$ of the total precipitation variance over SC during boreal winter. Therefore, revealing the relevant mechanisms of the intraseasonal precipitation over SC is of great significance to understand and predict the occurrence of wet winters.

The Madden-Julian oscillation (MJO) characterized by slow eastward propagating deep convection along the equator is the prominent physical mode over the tropics in the intraseasonal band (Madden and Julian 1972; Li et al. 2020). It was suggested that the MJO has a great influence on precipitation over SC during its cycle (Jia et al. 2011; Jeong et al. 2008; Li et al. 2014; Cui and Li 2021; Liu et al. 2020). The SC precipitation tends to significantly increase when enhanced MJO convection is located over the eastern Indian Ocean [i.e., MJO phase 2 and 3 defined in Wheeler and Hendon (2004)], and decrease when enhanced convection is over the western Pacific Ocean (i.e., MJO phase 6 and 7). 
Previous studies have devoted to understand the intraseasonal modulation of precipitation over East Asia by the MJO cycle, and several physical processes have been identified. One physical process that relates the MJO convection anomaly and the SC precipitation anomaly is the upper-level Rossby wave train from the tropics to the midlatitudes triggered by MJO diabatic heating (Liu and Yang 2010; Zhang 2013). In response to the enhanced convection over the eastern Indian Ocean during MJO phase 2-3, a pair of anticyclonic anomalies are excited symmetric about the equator west of the heating (Gill 1980), and the northern one over the Arabian Sea in turn induces a northeastward-propagating Rossby wave train to the midlatitudes. The wave train consists of an anomalous cyclone over China and an anomalous anticyclone over the middle of Japan; the cyclonic one is conductive to precipitation over SC (Hung et al. 2014). With the eastward propagation of MJO heat source, the wave train shifts eastward. In addition to the upper-level way, the MJO could also influence the SC precipitation through modulating lower-level moisture transport (e.g., Ren and Ren 2017). During phase 2-3 (phase 6-7), anomalous moisture convergence (divergence) due to intraseasonal southwesterly (northeasterly) wind anomaly in the lower troposphere is found over SC, which is conductive to positive (negative) rainfall anomaly (Jia et al. 2011). The southwesterly anomaly during phase 2-3 may be related to the simultaneous enhancement of the trough over the Bay of Bengal (Wang et al. 2011) and the western Pacific subtropical high (Zong et al. 2014). It is also suggested that the MJO convection could impact the SC precipitation through inducing meridional overturning circulation or local Hadley circulation (He et al. 2011, Seo et al. 2016, Peng et al. 2019; Chen Y-L et al. 2021).

Some more recent studies suggested the crucial role of the middle-and-high latitude intraseasonal oscillation (ISO) in the SC precipitation variation (e.g., Yao et al. 2015; Yao et al. 2020; Stan et al. 2017; Chen $X$ et al. 2021a; Zhu and Yang 2021). For example, using the real-time multivariate MJO (RMM) indices (Wheeler and Hendon 2004) to reconstruct the precipitation anomaly, Yao et al. (2015) showed that only $10 \%$ of the total subseasonal precipitation variability in SC is accounted for by the MJO. The rest variabilities are primarily due to cold surge phenomenon or the development of a Siberian high and cold-air outbreak in East Asia associated with a wave train from the North Atlantic (Park et al. 2014, Kim et al. 2020). However, the estimation by Yao et al. (2015) is based on the linear relationship between the MJO convection and extratropical circulations, which may underestimate the MJO effect associated with the nonlinear effect of the MJO (Bao and Hartmann 2014; Lin and Brunet 2018). Yao et al. (2020) analyzed the composited circulation evolutions associated with the intraseasonal precipitation events over SC in winters during 1979-2013. Their results suggested that the precipitation occurrence is mainly due to moisture transport induced by intraseasonal southerly wind anomaly in the lower troposphere, which is associated with a southward propagating low-pressure anomaly from polar region, whereas the MJO signal from the tropics is rarely seen.

Therefore, no consensus has been obtained on the relative contributions of the MJO and the mid-latitude ISO on the SC precipitation (Li and Mao 2018). Note that the conclusion by Yao et al. (2020) was based on composite analysis of all selected SC intraseasonal precipitation events during more than 30 years, which may neglect the diversity of precipitation origins. It is speculated that some precipitation events are more related to the tropical MJO while the others to mid-latitude ISO (Chen X et al. 2021). 
The present study attempts to examine the issue through categorizing the SC precipitation events based on their relationship with tropical convection anomalies. Furthermore, the physical processes responsible for the precipitation generation in different categories will be investigated respectively. The remainder of this study is organized as follows. The data and methods used in this study is described in Section 2. Section 3 presents classification of intraseasonal precipitation events in SC and Section 4 investigates the mechanisms for different precipitation clusters. The conclusion and discussion are shown in Section 5 .

\section{Data And Methods \\ 2.1 Data}

Daily high-resolution $\left(0.25^{\circ} \times 0.25^{\circ}\right)$ gridded precipitation data from the CN05.1 dataset (Wu and Gao 2013) provided by the National Climate Center in China is used to identify SC precipitation events. Daily winds, geopotential height and specific humidity are obtained from the ERA-interim dataset (Dee et al. 2011 ) at $1.5^{\circ} \times 1.5^{\circ}$ spatial resolution. Daily outgoing longwave radiation (OLR) data (Liebman and Smith 1996 ) with $2.5^{\circ} \times 2.5^{\circ}$ produced by National Oceanic and Atmospheric Administration (NOAA) polarorbiting satellites is utilized to represent tropical convections. All data used here are extracted for the same period of 1979-2016 and only the boreal winter season [November-March (NDJFM)] is focused on.

\subsection{Selecting the intraseasonal SC precipitation events}

Considering that the spectrum peak of SC precipitation is mainly observed in 10-30-day band (Yao et al. 2020) and that of MJO is in 30-60-day band (Madden and Julian 1972), here a 10-70-day bandpass filter (Duchon 1979) is applied to the daily precipitation and other variables to extract the intraseasonal anomalies. Prior to filtering, all fields are removed of the annual cycle. It is worth mentioning that we also tried the 10-30-day bandpass filter, and found similar results as shown in the following study.

Then, an intraseasonal precipitation index is constructed over SC [i.e., $\left(22^{\circ}-30^{\circ} \mathrm{N}, 110^{\circ}-120^{\circ} \mathrm{E}\right)$ ] where maximum intraseasaonal precipitation variance is found. An intraseasonal precipitation event is identified when the precipitation index exceeds one standard deviation and the day with the rainfall peak is marked as Day 0. According to this criteria, a total of 144 precipitation events are selected in boreal winter from 1979 to 2016.

\subsection{Categorization of the SC precipitation events}

To investigate the relative contributions of the tropical MJO and the mid-latitude ISO to the SC precipitation, we first identify those events that are closely related to the tropical convection anomalies. It is through applying the $\mathrm{K}$-means cluster analysis to the tropical intraseasonal OLR anomalies during the rainfall peak days of each event. Different tropical regions and rainfall peak days we have tried in calculation are shown in Table 1. Prior to cluster analysis, the OLR anomalies greater than $-5 \mathrm{~W} \mathrm{~m}^{-2}$ and less than $5 \mathrm{~W} \mathrm{~m}^{-2}$ are set to zero and a nine-point local smoothing is performed to remove small-scale 
noises. It shows that slight changes of the tropical regions and rainfall peak days yield very similar results. The 144 events can be optimally grouped into three clusters (referred to as Clusters 1-3, respectively) with silhouette values greater than 0.1 , while the rest ones are referred to as Cluster 4 .

Figure 1 displays the proportion of each cluster to the total precipitation events. On average, Clusters 1-4 account for $33 \%, 14 \%, 8 \%$ and $45 \%$ of the total precipitation events respectively, whereas slight changes of the domain and rainfall peak days only lead to small variations of the case numbers. Thus, we will only present the cluster result derived from the Day -2 to Day +2 averaged OLR anomalies over $20^{\circ} \mathrm{S}-20^{\circ} \mathrm{N}$, $40^{\circ} \mathrm{E}-160^{\circ} \mathrm{E}$ as a representative in the following study.

\section{Tropical And Mid-latitude Circulations In Each Cluster}

First, we compare the evolutions of precipitation anomalies averaged over SC from Day -15 to Day +15 among the four clusters (Fig. 2). The precipitation anomalies in all events turn from negative to positive on Day -4 and their magnitudes and horizontal patterns are of little difference (figures not shown).

Then, the evolutions of meridional advection of mean moisture by intraseasonal wind anomaly averaged over SC for each cluster is examined in Fig. 3. As mean moisture is maximum near the equator, positive (negative) moisture advection anomaly is induced by southerly (northerly) wind anomaly. All the clusters show significantly positive moisture advection anomaly over SC prior to Day -4 , suggesting that the intraseasonal southerly anomaly plays a crucial role in premoistening SC.

The correspondence of tropical convection anomalies to each cluster is examined in Fig. 4, in which the left panels display horizontal patterns of the tropical OLR anomalies on Day 0 and the right panels show their zonal evolutions from Day -25 to Day 25 along the equator $\left(20^{\circ} \mathrm{S}-20^{\circ} \mathrm{N}\right.$ average). In Cluster 1 , a zonal dipole pattern of OLR anomalies is prominent on Day 0 , with an enhanced convection anomaly over the equatorial eastern Indian Ocean and a suppressed one over the western Pacific Ocean (Fig. 4a). Such pattern resembles that observed in the MJO phase 2-3, as defined by Wheeler and Hendon (2004). In Cluster 2, an enhanced convection anomaly is seen over the Maritime Continent, while suppressed ones are over the Indian Ocean and near the date line, respectively (Fig. 4c). Such distribution is similar to that found in the MJO phase 4-5. Furthermore, the enhanced convection anomalies in these two clusters both display a continuous eastward propagation along the equator, which initiate from the Indian Ocean and dissipate near the date line (Figs. $4 \mathrm{~b}$ and $4 \mathrm{~d}$ ). These characteristics are identical to those in a typical MJO, although some phase lags can be found. In Cluster 3, a large area of suppressed convection anomaly is found over the eastern Indian Ocean and western Maritime Continent while a small area of enhanced convection anomaly is east of the Philippine Sea on Day 0 (Fig. 4e), but the convection anomalies do not propagate eastward continuously (Fig. 4f). The tropical convection anomalies are weak and scattered in Cluster 4 (Fig. 4g), and no significant signals could be found in the longitude-lagged time diagram (Fig. 4h). Thus, the first two clusters are accompanied by the MJO while the other ones are not.

Next, the correspondence of the mid-latitude ISO to each cluster is explored. Since Yao et al. (2020) revealed that the southward propagation of surface low pressure anomaly from the higher latitudes 
towards SC is responsible for the intraseasonal precipitation variation, Fig. 5 investigates the meridional propagation of $850-\mathrm{hPa}$ geopotential height anomalies averaged over $80-120^{\circ} \mathrm{E}$ in each cluster. It is of interest to observe that all events are accompanied by significant negative geopotential height anomalies propagating southward from the higher latitudes, which reach SC on Day 0, although some detailed difference may exist. Such finding is consistent with Yao et al. (2020).

Figure 6 further presents evolutions of the horizontal patterns of $850-\mathrm{hPa}$ geopotential height and wind anomalies from Day -8 to Day 0 with an interval of 2 days in each cluster. There are significant differences between Clusters 1-2 and Clusters 3-4. For Clusters 3-4, no significant geopotential height and wind anomalies can be found near the equator, but a large scale low-pressure anomaly is clearly seen over Euro-Asia continent in middle and high latitudes. The low pressure anomaly is near $60^{\circ} \mathrm{N}, 100^{\circ} \mathrm{E}$ on Day -8 and moves southward with time. The southwesterly wind anomaly across the eastern China on Day -6 which is crucial for SC premoistening as shown in Fig. 3 is clearly in association with the southward propagating low-pressure anomaly as the geostrophic wind response. This is consistent with the mechanism proposed by Yao et al. (2020).

In contrast, significant geopotential height and wind anomalies could be observed in the tropics in Clusters 1 and 2, showing the existence of the MJO. Furthermore, the southwesterly wind anomaly across the eastern China on Day - 6 in Cluster 1 looks rather related to the anomalous anticyclone over the WNP than to the low-pressure anomaly over East Asia, for the continental low-pressure anomaly and the associated geostrophic wind is located too north.

The above results suggest that the precipitation events in Clusters 3 and 4 are primarily triggered by the mid-latitude ISO, while those in Clusters 1 and 2 are closely related to the tropical MJO as well. Therefore, we will further explore how the MJO trigger the precipitation events in the following section. Since Cluster 1 corresponds to an enhanced convection anomaly over the Indian Ocean and Cluster 2 over the Maritime Continent, hereafter they are referred to as the IO group and MC group, respectively.

\section{Mechanisms For The Mjo Impact On Sc Precipitation Events 4.1 10 Group}

Figure 7 presents composite horizontal evolutions of tropical OLR anomalies along with the $850-\mathrm{hPa}$ circulation and geopotential height anomalies from Day -10 to Day +1 shown by every 3-day average for IO group. On Day -10 to -8 (Fig. 7a), when SC precipitation is negative, a northeasterly wind anomaly is across the eastern coast of China. It is due to a weak large-scale high pressure anomaly covering the southern and eastern Asia. At this time, a narrow zonal belt of suppressed convection anomaly is over the equatorial eastern Indian Ocean and western Pacific Ocean and a weak enhanced convection anomaly is east of the dateline, with an equatorial easterly (westerly) wind anomaly over the Indian (western Pacific) Ocean. 
On Day -7 to -5 (Fig. 7b), which is the premoistening stage for SC, the prevailing wind anomaly over the eastern coast of China is southwesterly. Such wind is clearly part of the anomalous anticyclone over the WNP, since the main body of the mid-latitude ISO of low pressure anomaly is still north of $45^{\circ} \mathrm{N}$. Compared to Fig. 7a, the dipole MJO convection anomalies shift eastward with the western pole strengthening and the eastern pole weakening. As a small area of enhanced convection anomaly emerges near the equatorial western Indian Ocean, the easterly wind anomaly intensifies over the Indian Ocean. The WNP anticyclone is a response to the suppressed convection anomaly east of the MC (Gill 1980).

After precipitation is triggered over SC on Day -4 , the southwesterly wind anomaly near the eastern coast of China intensifies (Figs. 7c and 7d), which further facilitates moisture transport into SC and favors for strengthening and maintaining the precipitation. The overall MJO convections over the Indo and western Pacific Ocean shift eastward and intensify; meanwhile, the mid-latitude ISO of large-scale low pressure anomaly moves southward and covers most land of the southern and eastern Asia. Thus, the amplified southwesterly is jointly contributed by the WNP anomalous anticyclone related to the MJO as well as the southward propagating mid-latitude ISO.

Figure 8 further displays the evolutions of upper-tropospheric circulations in association with 10 group. On Day -10 to -8 (Fig. 8a), a westerly (easterly) anomaly is prominent over the tropical Indian Ocean (central Pacific Ocean) as a response to the suppressed MJO convection anomaly near the MC, and a significant anomalous cyclone is over the southern Asia. On Day -7 to -5 (Fig. 8b), a wave train is clear over the Asian land with an anomalous anticyclone centered north of the Arabian Sea, an anomalous cyclone north of the Bay of Bengal and an anomalous anticyclone over the northeastern China. The wave train propagates eastward in pace with the MJO convection anomalies (see Figs. 8c and 8d). As suggested by previous studies (e.g., Hung et al. 2014), such wave train is excited by the MJO heating. Then, how does this wave train trigger the SC precipitation? It is of interest to observe a significant area of divergence anomaly over SC in upper troposphere on Day -7 to -5 , which is related to the Rossby wave train (Fig. 8f). Such divergence is conductive to air rise prior to precipitation. Note that the precipitation then feedbacks to intensify the upper-level divergence anomaly after Day -4 (see Figs. $8 \mathrm{~g}$ and $8 \mathrm{~h}$ ).

To sum up, the intraseasonal SC precipitation events in IO group are primarily triggered by the MJOrelated lower- and upper-tropospheric circulations, while the southward moving mid-latitude ISO helps maintain and enhance them through jointly contributing to the southwesterly anomaly along the coast of SC.

\subsection{Group}

Figures 9 and 10 are same as Figs. 7 and 8, but for MC group. On Day -10 to -8 , a weak northerly wind anomaly prevails along the shore of eastern China in lower troposphere (Fig. 9a) and it turns into a weak southerly wind anomaly on Day -7 to -5 (Fig. 9b), which begins to transport moisture into SC (Fig. 3). In contrast to the $\mathrm{IO}$ group, there is enhanced MJO convection anomaly over the Maritime Continent and a large area of low-pressure anomaly over the tropical western Pacific Ocean during the SC premoistening 
stage for the MC group (Fig. 9b). Therefore, the lower-level southerly wind anomaly over the eastern China is not due to the MJO circulation. It is probably in association with the low-pressure anomaly propagating from higher latitudes. With the southward movement of the large-scale low pressure anomaly, the southerly wind anomaly near SC intensifies on Day -4 to Day +1 (Figs. 9c and 9d).

In the upper troposphere (Fig. 10), significant wave trains are seen in the middle latitudes which are induced by the MJO convection anomalies. On Day -10 to -8 (Fig. 10a), significant easterly wind anomaly over the equatorial western Indian Ocean and an anomalous anticyclonic circulation over the Arabian Peninsula are directly excited by the enhanced MJO convection anomaly over the eastern Indian Ocean. To the east of this anticyclone, significant divergence anomaly is near Bangladesh (Fig. 10e). With the eastward propagation of the MJO convection, the anomalous anticyclone and the associated divergence anomaly also shift eastward. On Day -7 to -5 (Fig. 10f), the divergence anomaly moves to SC, which is conductive to air rise and provides favorable condition for generating precipitation. After precipitation occurs, the upper-level divergence anomaly further intensifies (Figs. $10 \mathrm{~g}$ and $10 \mathrm{~h}$ ).

In conclusion, the SC precipitation in 10 group is jointly triggered by the lower-tropospheric southerly wind anomaly related to the southward moving low-pressure anomaly from mid-high latitudes and uppertropospheric divergence anomaly in association with the MJO wave train.

\section{Summary}

The southern China (SC) has strong intraseasonal precipitation variation in boreal winter. Some studies emphasized that it is strongly modulated by the eastward propagating MJO convection anomalies near the equator, but some reported that the mid-latitude ISO is of much more significance while the impact from the MJO is very limited. The current study aims to distinguish the relative contributions from the MJO and the mid-latitude ISO to SC precipitation through analyzing observational data.

Firstly, we identify 144 strong intraseasonal SC precipitation events from November to March during 1979-2016. Then, these events are categorized by means of cluster analysis based on their relationship with the intraseasonal OLR anomalies over the tropical Indo-Pacific Ocean during the rainfall peak days. It shows that about $47 \%$ of the precipitation events (Clusters 1 and 2) are accompanied by the eastward propagation of MJO, while the rest ones (Clusters 3 and 4), accounting for about $53 \%$ of the total events, are not. All these events have similar evolutions in precipitation anomalies and witness significant southerly wind anomalies along the shore of the eastern China prior to precipitation initiation, which premoistens SC through transporting moisture from the South China Sea northward.

For those events not accompanied by the MJO, the emergence of southerly wind anomaly near SC is due to the southward propagation of an anomalous cyclone over the Asian continent, which is in geostrophic balance with the large-scale low-pressure anomaly propagating southward from the higher latitudes. In other words, these intraseasonal precipitation events are due to mid-latitude ISO. This finding is consistent with Yao et al. (2020). 
The rest events can be divided into two categories according to different locations of the MJO convection anomaly. One category (i.e., Cluster 1 or 10 group), accounting for about $33 \%$ of the total intraseasonal precipitation events, corresponds to enhanced MJO convection anomaly over the eastern Indian Ocean. The other category (i.e., Cluster 2 or MC group), accounting for about $14 \%$ of the total intraseasonal precipitation events, corresponds to enhanced MJO convection anomaly over the Maritime Continent.

The SC precipitation in 10 group is primarily triggered by the MJO related circulation anomalies in both the lower and upper troposphere. In the lower troposphere, the anomalous anticyclone over the WNP as a response to the MJO suppressed convection anomaly over the equatorial western Pacific contributes to the southwesterly wind anomaly near the shore of the eastern China that advects moisture to SC. In the upper troposphere, the extratropical wave train excited by the MJO enhanced convection anomaly over the Indian Ocean induces divergence over SC, which provides favorable condition for ascending motion. The large-scale low pressure anomaly moving southward from middle and high latitudes contributes to maintain and enhance the precipitation anomaly through jointly contributing to the southwesterly anomaly along the coast of SC.

For the MC group, both the southward moving mid-latitude ISO and the MJO jointly contribute to triggering SC precipitation. The MJO impacts the SC mainly through inducing upper-level divergence over $\mathrm{SC}$, but not contributing to the lower-level southerly wind anomaly along the shore of the eastern China.

Our current study clearly distinguishes the impacts from the MJO and the mid-latitude ISO on the initiation of the intraseasonal SC precipitation events through cluster analysis of the observational data. But the related mechanisms may need to be verified through numerical experiments in future studies.

\section{Declarations}

\section{Acknowledgements.}

This work was supported by National Natural Science Foundation of China (42088101 and 41975108), NOAA grant NA180AR4310298 and NSFC-Shandong Joint Fund for Marine Science Research Centers (U1606405).

\section{Funding}

This work was supported by National Natural Science Foundation of China (42088101 and 41975108), NOAA grant NA180AR4310298 and NSFC-Shandong Joint Fund for Marine Science Research Centers (U1606405).

\section{Competing Interests}

The authors have no relevant financial or non-financial interests to disclose.

\section{Author Contributions}


LW designed the original ideas presented in this manuscript. JJ conducted the analysis. $L W$ and JJ interpreted the results and wrote the manuscript. TL participated in improvement of the manuscript. All authors read and approved the final manuscript.

\section{Data Availability}

The data analyzed in this study are available from the author upon reasonable request.

\section{References}

1. Bao M, Hartmann DL (2014) The response to MJO-like forcing in a nonlinear shallow-water model. Geophys Res Lett 41:1322-1328. https://doi.org/10.1002/2013GL057683

2. Chen X, Ling J, Li C, et al (2021) Different Impacts of Madden-Julian Oscillation on Winter Rainfall over Southern China. J Meteorol Res 35:271-281. https://doi.org/10.1007/s13351-021-0138-7

3. Chen Y-L, Sui C-H, Chang C-P, Tseng K-C (2021) Effect of the MJO on East Asian winter rainfall as revealed by an SVD analysis. Journal of Climate 1-54. https://doi.org/10.1175/JCLI-D-20-0941.1

4. Cui, J.-X., T. Li (2021) Changes in MJO characteristics and impacts in the past century. Journal of Climate, in press.

5. Duchon CE (1979) Lanczos filtering in one and two dimensions. Journal of Applied Meteorology and Climatology 18:1016-1022

6. Gill AE (1980) Some simple solutions for heat-induced tropical circulation. Quarterly Journal of the Royal Meteorological Society 106:447-462

7. Hong C-C, Li T (2009) The Extreme Cold Anomaly over Southeast Asia in February 2008: Roles of ISO and ENSO*. Journal of Climate 22:3786-3801. https://doi.org/10.1175/2009JCLI2864.1

8. Hung C, Lin H-J, Hsu H-H (2014) Madden-Julian Oscillation and the Winter Rainfall in Taiwan. Journal of Climate 27:4521-4530. https://doi.org/10.1175/JCLI-D-13-00435.1

9. Jeong J-H, Kim B-M, Ho C-H, Noh Y-H (2008) Systematic Variation in Wintertime Precipitation in East Asia by MJO-Induced Extratropical Vertical Motion. Journal of Climate 21:788801. https://doi.org/10.1175/2007JCLI1801.1

10. Jia X, Chen L, Ren F, Li C (2011) Impacts of the MJO on winter rainfall and circulation in China. Adv Atmos Sci 28:521-533. https://doi.org/10.1007/s00376-010-9118-z

11. Kim S, Kug J-S, Seo K-H (2020) Impacts of MJO on the Intraseasonal Temperature Variation in East Asia. Journal of Climate 33:8903-8916. https://doi.org/10.1175/JCLI-D-20-0302.1

12. Li C, Ling J, Song J, et al (2014) Research progress in China on the tropical atmospheric intraseasonal oscillation. Journal of Meteorological Research 28:671-692

13. Li, J.Y. and J.Y. Mao, (2018) The impact of interactions between tropical and mid-latitude intraseasonal oscillations around the Tibetan Plateau on the 1998 Yangtze floods. Quarterly Journal of the Royal Meteorological Society. 144: 1123-1139 
14. Li T, Ling J, Hsu P-C (2020) Madden-Julian oscillation: Its discovery, dynamics, and impact on East Asia. Journal of Meteorological Research 34:20-42

15. Lin H, Brunet G (2018) Extratropical Response to the MJO: Nonlinearity and Sensitivity to the Initial State. J Atmos Sci 75:219-234. https://doi.org/10.1175/JAS-D-17-0189.1

16. Liu D, Yang X (2010) Mechanism responsible for the impact of Madden-Julian Oscillation on the wintertime rainfall over eastern China [J]. Scientia Meteorologica Sinica 5:

17. Liu, F., Ouyang, Y., Wang, B. et al., (2020) Seasonal evolution of the intraseasonal variability of China summer precipitation. Clim. Dyn., https://doi.org/10.1007/s00382-020-05251-0

18. Liu Y, Hsu P-C (2019) Long-term changes in wintertime persistent heavy rainfall over southern China contributed by the Madden-Julian Oscillation. Atmospheric and Oceanic Science Letters 12:361368

19. Madden RA, Julian PR (1972) Description of global-scale circulation cells in the tropics with a 40-50 day period. Journal of Atmospheric Sciences 29:1109-1123

20. Park T-W, Ho C-H, Deng Y (2014) A synoptic and dynamical characterization of wave-train and blocking cold surge over East Asia. Clim Dyn 43:753-770. https://doi.org/10.1007/s00382-0131817-6

21. Peng J, Dadson S, Leng G, et al (2019) The impact of the Madden-Julian Oscillation on hydrological extremes. Journal of Hydrology 571:142-149

22. Ren H-L, Ren P (2017) Impact of Madden-Julian Oscillation upon Winter Extreme Rainfall in Southern China: Observations and Predictability in CFSv2. Atmosphere 8:192. https://doi.org/10.3390/atmos8100192

23. Seo K-H, Lee H-J, Frierson DMW (2016) Unraveling the Teleconnection Mechanisms that Induce Wintertime Temperature Anomalies over the Northern Hemisphere Continents in Response to the MJO. Journal of the Atmospheric Sciences 73:3557-3571. https://doi.org/10.1175/JAS-D-16-0036.1

24. Stan C, Straus DM, Frederiksen JS, et al (2017) Review of Tropical-Extratropical Teleconnections on Intraseasonal Time Scales: The Subseasonal to Seasonal (S2S) Teleconnection Sub-Project. Rev Geophys 55:902-937. https://doi.org/10.1002/2016RG000538

25. Tao S, Wei J (2008) Severe snow and freezing-rain in January 2008 in the southern China. Climatic and Environmental Research 13:337-350

26. Wang T, Yang S, Wen Z, et al (2011) Variations of the winter India-Burma Trough and their links to climate anomalies over southern and eastern Asia. Journal of Geophysical Research: Atmospheres 116:

27. Wheeler MC, Hendon HH (2004) An All-Season Real-Time Multivariate MJO Index: Development of an Index for Monitoring and Prediction. Mon Wea Rev 132:1917-1932. https://doi.org/10.1175/15200493(2004)132<1917:AARMMI>2.0.C0;2

28. Wu J, Yuan Z, Qian Y, Liang C (2009) The role of intraseasonal oscillation in the southern-China snowstorms during January 2008 [J]. J Trop Meteor 25:103-112 
29. Zhu T, Yang J (2021) Two types of mid-high-latitude low-frequency intraseasonal oscillation near Ural Mountain in boreal summer. J. Climate. DOI: 10.1175/JCLI-D-20-0589.1

30. Yao S, Huang Q (2016) An analysis of extreme intraseasonal rainfall events during January-March 2010 over eastern China. Dynamics of Atmospheres and Oceans 75:2232. https://doi.org/10.1016/j.dynatmoce.2016.04.001

31. Yao S, Huang Q, Li T, Zhang C (2014) The intraseasonal oscillations of precipitation and circulations from January to March in 2010 in East Asia. Meteorology and Atmospheric Physics 123:67-79

32. Yao S, Tong Q, Li T, Gong K (2020) The 10-30-day oscillation of winter rainfall in southern China and its relationship with circulation patterns in different latitudes. Int J Climatol 40:32683280. https://doi.org/10.1002/joc.6396

33. Yao Y, Lin H, Wu Q (2015) Subseasonal Variability of Precipitation in China during Boreal Winter. Journal of Climate 28:6548-6559. https://doi.org/10.1175/JCLI-D-15-0033.1

34. Zhang C (2013) Madden-Julian Oscillation: Bridging Weather and Climate. Bull Amer Meteor Soc 94:1849-1870. https://doi.org/10.1175/BAMS-D-12-00026.1

35. Zong H, Bueh C, Ji L (2014) Wintertime extreme precipitation event over southern China and its typical circulation features. Chin Sci Bull 59:1036-1044. https://doi.org/10.1007/s11434-014-0124-x

\section{Tables}

Table 1 List of days and regions selected for the cluster analysis.

Days Regions

Day 0

$20^{\circ} \mathrm{N}-20^{\circ} \mathrm{E}, 30^{\circ}-180^{\circ} \mathrm{E}$

Day -3 to day 3 average

$20^{\circ} \mathrm{N}-20^{\circ} \mathrm{E}, 30^{\circ}-180^{\circ} \mathrm{E}$

Day -2 to day 2 average

$30^{\circ} \mathrm{N}-30^{\circ} \mathrm{E}, 30^{\circ}-180^{\circ} \mathrm{E}$

Day -2 to day 2 average

$20^{\circ} \mathrm{N}-20^{\circ} \mathrm{E}, 40^{\circ}-160^{\circ} \mathrm{E}$

\section{Figures}




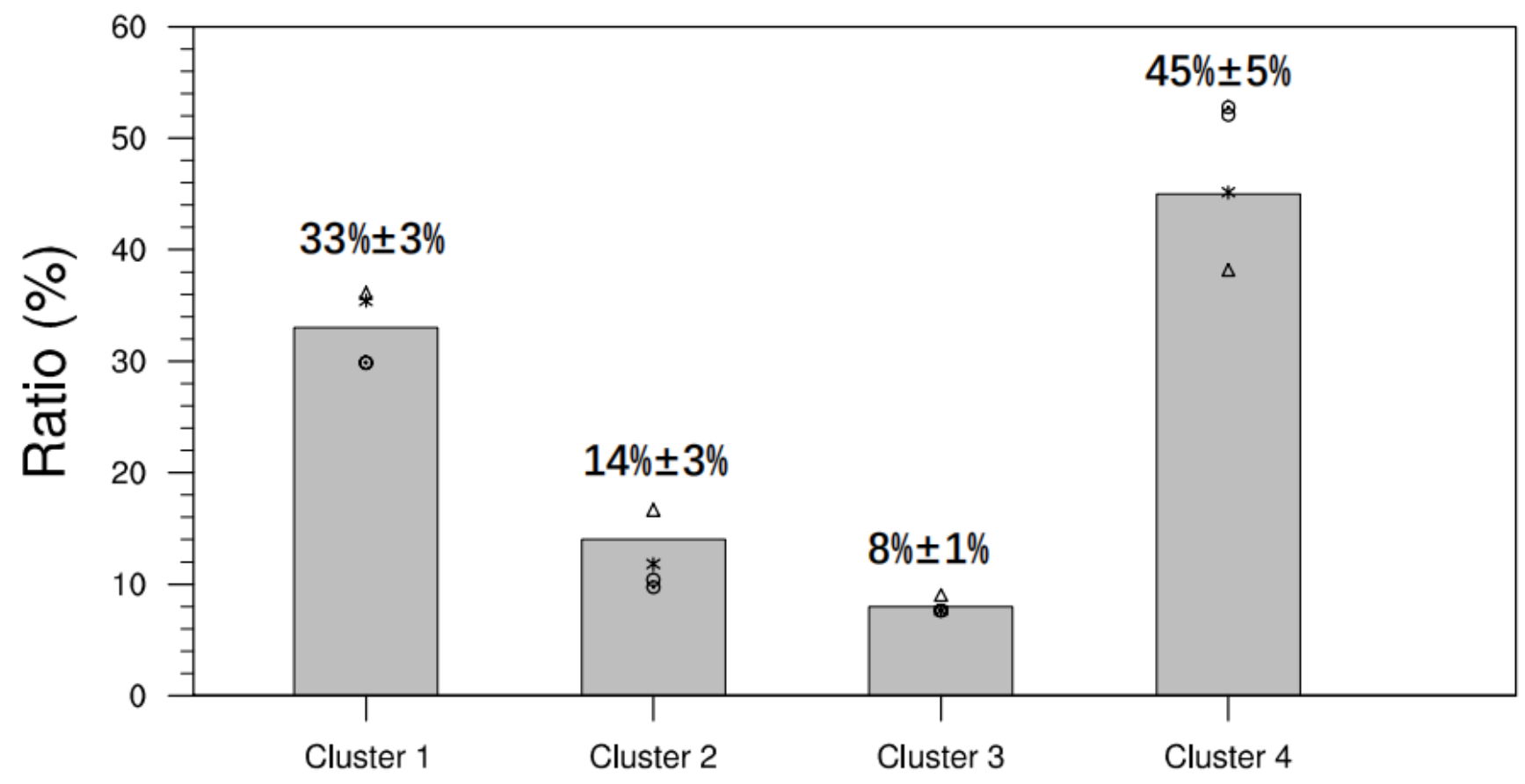

Figure 1

Ratio of intraseasonal SC precipitation events to the total events for each cluster. Markers denote the results based on different days and regions listed in Table 1, while the bars represent the average. The ratio value and the variation range for each cluster are marked on top of each bar. 


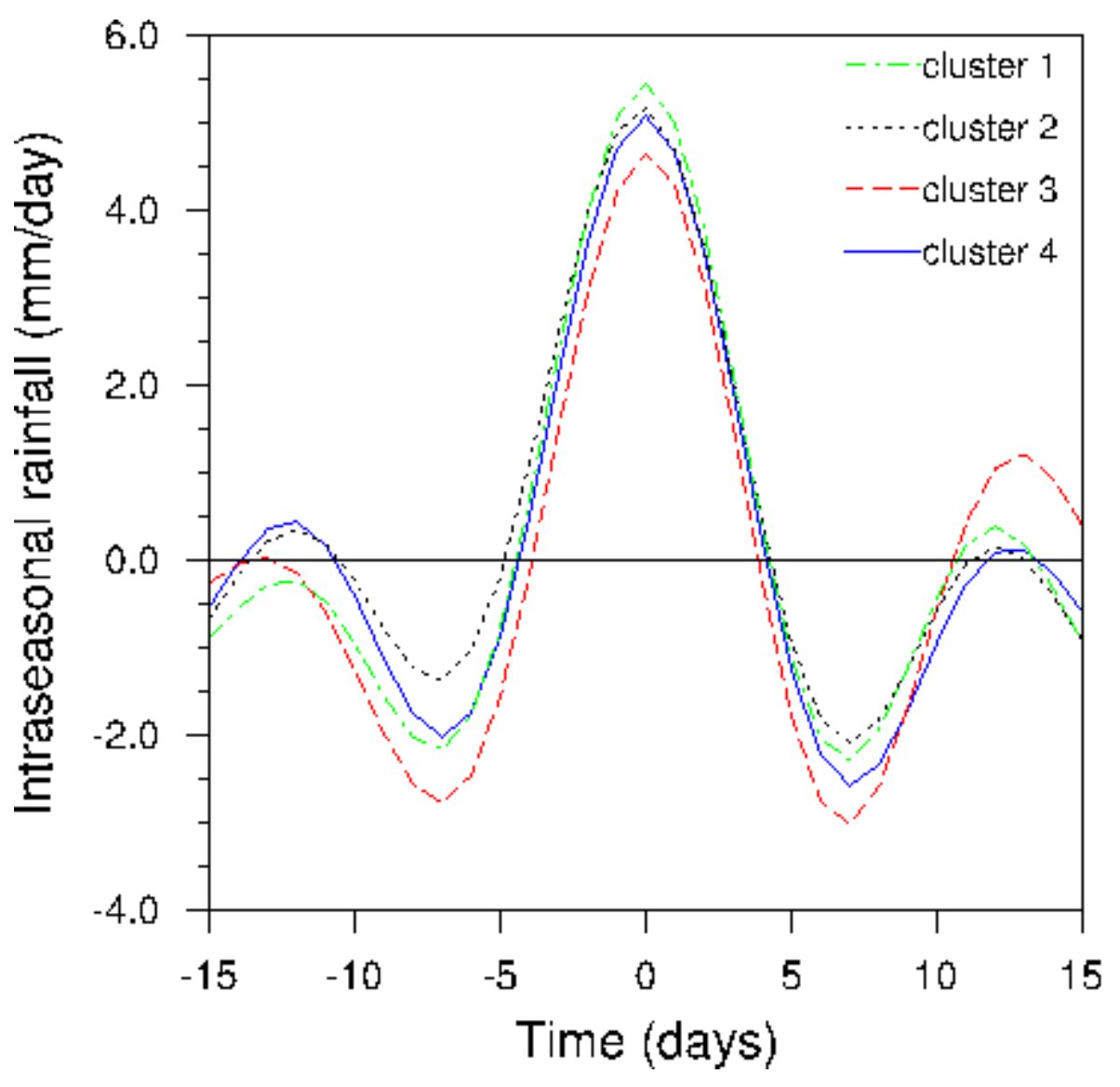

Figure 2

Composite evolutions of intraseasonal rainfall anomalies (unit: $\mathrm{mm} \bullet$ day $^{-1}$ ) averaged over SC $\left(22-30^{\circ} \mathrm{N}\right.$, $110-120^{\circ} \mathrm{E}$ ) from Day -15 to Day +15 . "0" on the horizontal axis is the peak day of the rainfall, and negative (positive) values mean the days before (after) the peak day. The green dotted line is for Cluster 1 , the black dotted line is for Cluster 2, the red dotted line is for Cluster 3 and the blue solid line is for Cluster 4. 

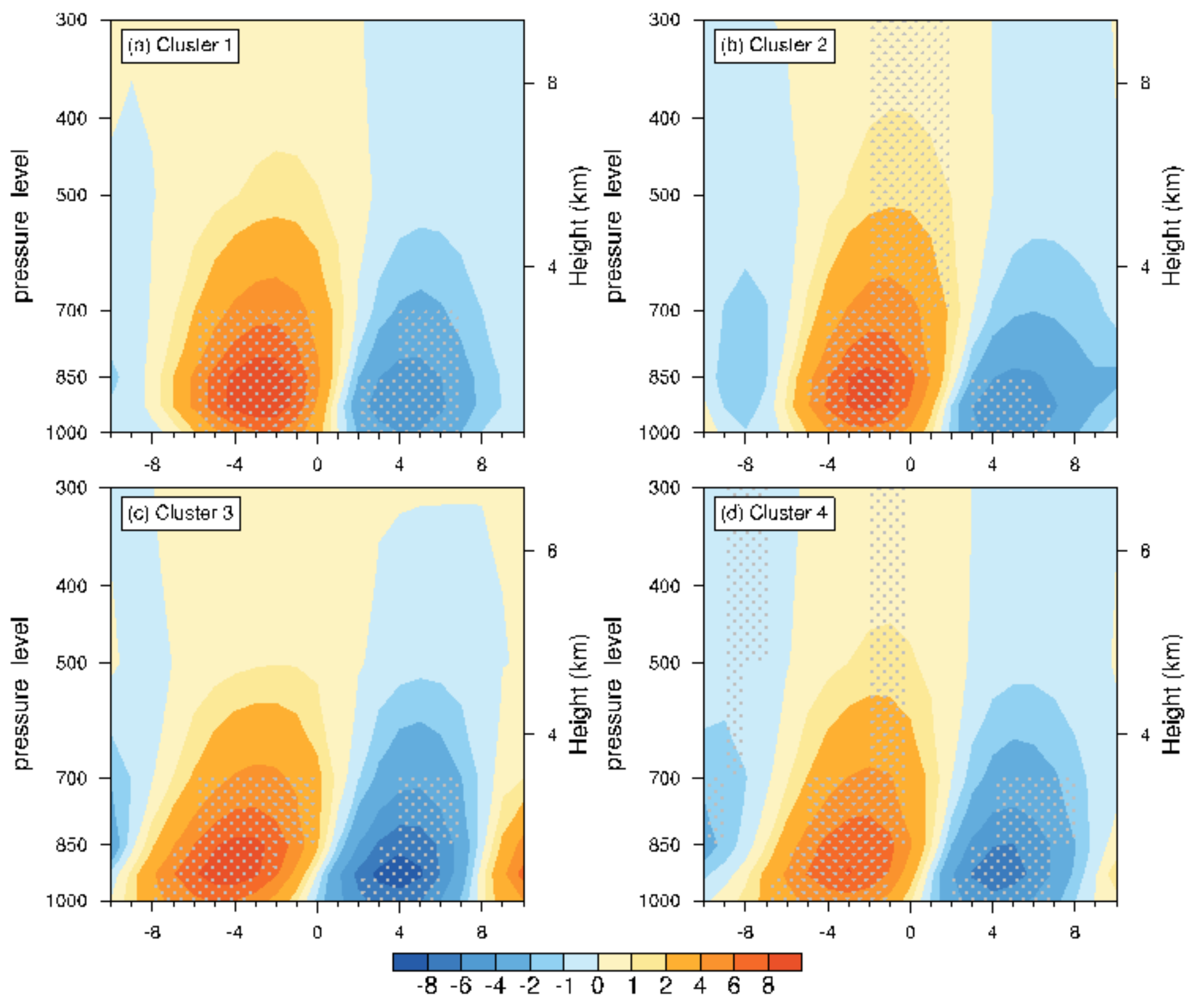

Figure 3

Latitude-time profile of the advection of mean moisture by intraseasonal meridional wind anomaly [unit: $\left.10^{9} \mathrm{~kg} \cdot \mathrm{kg}^{-1} \cdot \mathrm{s}^{-1}\right]$ for Clusters $1-4$, respectively. The regions exceeding the $95 \%$ confidence level are stippled.

\section{Figure 4}

Horizontal pattern of intraseasonal OLR anomaly (unit: $\mathrm{W} \cdot \mathrm{m}^{-2}$ ) on Day 0 and its zonal propagation along the equator $\left(20^{\circ} \mathrm{S}-20^{\circ} \mathrm{N}\right.$ average) from Day -25 to Day 25 for $(\mathrm{a}, \mathrm{b})$ Cluster $1,(\mathrm{c}, \mathrm{d})$ Cluster 2, (e, f) Cluster 3 and $(\mathrm{g}, \mathrm{h})$ Cluster 4 . The regions exceeding the $95 \%$ confidence level are stippled. 

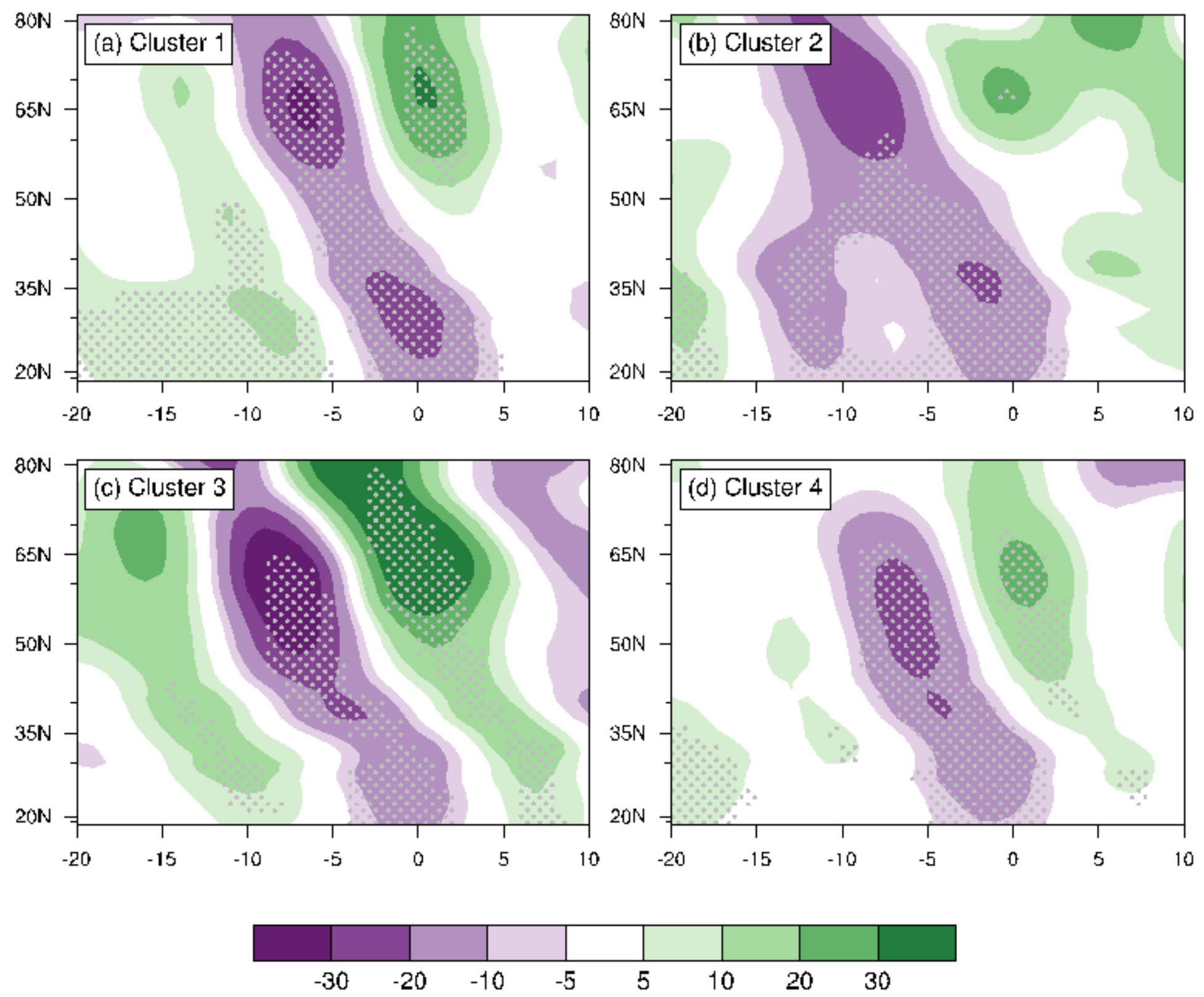

\section{Figure 5}

Latitude-lagged time evolutions of intraseasonal geopotential height anomaly (unit: gpm) at $850 \mathrm{hPa}$ averaged over $80-120^{\circ} \mathrm{E}$. (a)-(d) represent Cluster 1 to Cluster 4, respectively. The regions exceeding the $95 \%$ confidence level are stippled. 
Horizontal evolutions of 850-hPa geopotential height (shading; unit: gpm) and wind (vector; unit: $\mathrm{m} \cdot \mathrm{s}^{-1}$ ) anomalies for each cluster from Day -8 to Day 0 , with an interval of 2 days. Only the geopotential height anomalies with a $90 \%$ confidence level are shown. Dark vectors denote those wind anomalies significant with a $90 \%$ confidence level, the rest are shown in grey.

\section{Figure 7}

Horizontal evolutions of 850-hPa geopotential height (shading; unit: gpm), wind anomalies (vector; unit: $\left.\mathrm{m} \cdot \mathrm{s}^{-1}\right)$ and tropical $\left(20^{\circ} \mathrm{S}-20^{\circ} \mathrm{N}\right)$ OLR anomalies (contour; units: $\mathrm{W} \cdot \mathrm{m}^{-2}$ ) for 10 group during (a) Day -10 to -8 , (b) Day -7 to -5 , (c) Day -4 to -2 , (d) Day -1 to +1 . Only the geopotential height anomalies with a $90 \%$ confidence level are shown. Dark vectors denote those wind anomalies significant with a $90 \%$ confidence level, the rest are shown in grey.

\section{Figure 8}

(left) Horizontal evolutions of 200-hPa geopotential height (shading; unit: gpm), wind anomalies (vector; unit: $\mathrm{m} \cdot \mathrm{s}^{-1}$ ) and tropical $\left(20^{\circ} \mathrm{S}-20^{\circ} \mathrm{N}\right.$ ) OLR anomalies (contour; unit: $\mathrm{W} \cdot \mathrm{m}^{-2}$ ) for 10 group during (a) Day -10 to -8 , (b) Day -7 to -5 , (c) Day -4 to -2 , (d) Day -1 to +1 . The right panels are same as the left ones, but of 200-hPa divergence anomalies (shading; units: $\mathrm{s}^{-1}$ ). Only the geopotential height anomalies with a $90 \%$ confidence level are shown. Divergence anomalies with a 90\% confidence level are stippled. Wind anomalies with a $90 \%$ confidence level are shown in dark vectors; the rest are shown in grey.

\section{Figure 9}

Same as Fig. 7, but for MC group.

\section{Figure 10}

Same as Fig. 8, but for MC group. 